\title{
7348
}

NASA Technical Memorandum 105881

\section{Probabilistic Evaluation of Fuselage-Type Composite Structures}

Michael C. Shiao

Sverdrup Technology, Inc.

Lewis Research Center Group

Brook Park, Ohio

and

Christos C. Chamis

National Aeronautics and Space Administration

Lewis Research Center

Cleveland, Ohio

Prepared for the

Ninth DoD/NASA/FAA Conference on Fibrous Composites

Reno, Nevada, November 3-7, 1991 


\title{
PROBABIISTIC EVAUUATION OF FUSEIAGE-TYPE COMPOSIIE SIRUCIURES
}

\author{
Michael C. Shiao \\ Sverdrup Technology, Inc. \\ Lewis Research Center Group \\ Brookpark, Ohio \\ Christos C. Chamis \\ NASA Lewis Research Center \\ Cleveland, Ohio
}

\begin{abstract}
A methodology is developed to computationally simulate the uncertain behavior of composite structures. Uncertain behavior is the consequence of the random variation (scatter) of the primitive (independent random) variables at the constituent, ply, laminate and structural levels. This methodology is implemented in the IPACS (Integrated Probabilistic Assessment of composite Structures) computer code. A fuselage-type composite structure is analyzed to demonstrate the code's capability. The probability distribution functions of structural responses are computed. Sensitivity of a given structural response to each primitive variable is also determined from the analyses.
\end{abstract}

\section{INIRODUCTION}

Composites are an important class of engineering material in aerospace design. Their outstanding mechanical properties, particularly the high strength to density ratio, are very attractive to the aerospace industry. They also posses excellent durability and corrosion-resistance. The mechanical properties of composite materials are derived from those of fiber and matrix constituents, which depend on a wide variety of variables. These variables include, for example, fiber and matrix material properties (constituent level), fabrication variables such as fiber volume ratio, void volume ratio, ply orientation, ply thickness (ply level). These primitive variables are statistical in nature, therefore, the mechanical properties of a composite material should be quantified probabilistically. As a consequence, the behavior of composite structures shows considerable scatter from its average value. 
Traditionally, a "safety factor" is used in designs to account for these unpredictable behavior. However, this approach results in either an overconservative design or an unsafe design. Because of the need in design for a probabilistic assessment capability for composite structures, a methodology was developed at the NASA Lewis Research Center. The methodology, incorporated into computer code IPACS, is based upon the identification of uncertain variables at every structural level. The uncertain variables are then filtered through an analyzer which combines the composite mechanics, structural mechanics and probability theory to determine the probability distribution functions of desired structural responses.

These types of problems can normally be solved by the Monte Carlo simulation method. But, it is computationally expensive. In order to save computational time, the newly developed methodology uses special probability algorithms to provide an efficient and affordable way for the probabilistic assessment of uncertain composite structures.

A fuselage-type composite structure is analyzed to demonstrate the code's capability. Buckling, natural frequency and static analyses are performed. The probability distributions for critical buckling load, first natural frequency, nodal displacement at free end, nodal strain and stress at fixed end are computed. The sensitivity of a given structural response to each primitive variable is also determined.

PROBABUISTIC ASSESSMENT OF COMPOSTTE STRUCTURES

Probabilistic assessment of composite structures requires the identification of uncertainties within the model at the micro and macro levels. For example, at the constituent level, the uncertain primitive variables include the material properties of fiber and matrix. At the ply level, the uncertain primitive variables include fiber and void volume ratio, ply orientation and ply thickness. At the structural level, uncertainties in the loadings, temperature, geometry or boundary conditions may also be included. Each primitive variable is characterized by a characteristic probability distribution function and is input into an analyzer that combines composite mechanics, structural mechanics and probability theory. From the analysis, structural responses and material properties are obtained which are represented by probability distribution functions. The computational approach is illustrated schematically in figure 1. 
The analysis modules which comprise the IPACS code are described briefly in the following section.

\section{COMPUTER CODE IPACS}

IPACS is a computer code for probabilistic analysis of composite structures. It integrates several NASA in-house computer programs developed in recent years such as COBSTRAN (Composite Blade STRuctural ANalyzer (ref. 1), PICAN (Probabilistic Integrated Composite Analyzer) and PROCSAN (PRObabilistic Composite Structural ANalyzer). COBSTRAN generates finite element models for composite structural analyses. PICAN determines the perturbed and probabilistic composite material properties at the ply and laminate level. PROCSAN determines the perturbed and probabilistic structural response at structural, laminate and ply levels. PICAN and PROCSAN use the same module, FPI (Fast Probability Integrator) (ref. 2, 3), for probabilistic calculation. The architecture of THE IPACS software system is depicted in figure 2. Details of PICAN, PROCSAN and FPI modules are explained in the following.

\section{PICAN MODULE}

PICAN has evolved from the deterministic composite mechanics code ICAN (Integrated Composite Analyzer) (ref. 4). It performs a comprehensive multilevel perturbation and probabilistic analysis of composite material properties considering the uncertainties in the primitive variables at all composite scales. Perturbed material properties are computed at every level corresponding to each of the perturbed primitive variables. With this information, mathematical functions are developed to represent the relationships between the material properties and the primitive variables. The functions can be expressed by

$$
M_{p}=a_{0}+\sum_{i=1}^{N} a_{i} X_{i}
$$

if the relationship is linear, or by 


$$
M_{p}=a_{0}+\sum_{i=1}^{n} a_{i} x_{1}+\sum_{i=1}^{n} b_{i} x_{i}^{2}
$$

if the relationship is nonlinear, where $\mathrm{M}_{\mathrm{p}}$ is any material property; $\mathrm{n}$ is the number of primitive variables; $x_{i}$ 's are primitive variables; and $a_{0}, a_{i}, b_{i}$ are constants. PICAN uses the probability distribution functions of the primitive variables, along with eq. (1) or (2) to calculate the probability distribution function for any material property.

PROCSAN

PROCSAN is a finite element module for the perturbation and probabilistic structural analysis considering all possible uncertainties including uncertain composite material properties. From laminate theory, the relationship between resultant forces and strains are shown in equation (3).

$$
\left\{\begin{array}{l}
N \\
M
\end{array}\right\}=\left[\begin{array}{ll}
A & C \\
C & D
\end{array}\right]\left\{\begin{array}{l}
\epsilon \\
\kappa
\end{array}\right\}
$$

where $\mathrm{N}$ are the resultant forces and $\mathrm{M}$ are the resultant moments; $\varepsilon$ are the inplane strains and $\mathrm{k}$ are the curvatures. For a set of $\mathrm{A}, \mathrm{C}$ and $\mathrm{D}$ matrices determined using perturbed primitive variables, the corresponding structural responses are computed by PROCSAN. Therefore, the structural responses and the primitive variables can be related by mathematical functions as expresses by

$$
R=a_{0}+\sum_{i=1}^{n} a_{i} X_{i}
$$

if the relationship is linear, or by 


$$
R=a_{0}+\sum_{i=1}^{n} a_{i} X_{i}+\sum_{i=1}^{n} b_{i} X_{i}^{2}
$$

if the relationship is nonlinear, where $\mathrm{R}$ is structural responses. The probability distribution functions of structural responses will be similarly determined by probabilistic methods outline above.

\section{FPI MODULE}

The FPI module evolved from the probability algorithm FORM (First Order Second Moment Reliability Method). After the perturbation study, a database is created. The relationship between the structural responses and the primitive variables can be determined numerically by FPI. Together with the probability distribution functions of primitive variables, FPI computes the cumulative distribution functions (cdf) of structural responses.

\section{IPACS STMULATION}

The uncertain primitive variables at constituent, ply, laminate and structural levels are first identified before performing a probabilistic assessment of composite structures using IPACS. These variables are then selectively perturbed several times in order to create a database for the determination of the relationship between the desired structural response (or the desired material property) and the primitive variables. For a given set of perturbed primitive variable, micro mechanics theory is applied to determine the corresponding perturbed mechanical properties at the ply and laminate level. Laminate theory is then used to determine the perturbed A, C and D matrices in equation (3). A finite element perturbation analysis is performed to determine the perturbed structural responses corresponding to the perturbed A, C and D matrices. This process is repeated until enough data is generated and the proper relationship between structural responses and primitive variables can be determined.

With the known probabilistic distributions of the primitive variables and a relationship between the structural response and the primitive variables, fast probability integration is performed. For every discrete response value, a corresponding cumulative probability can be computed quickly by FPI. This 
process is repeated until the cumulative distribution function can be appropriately represented. The probabilistic material properties at ply and laminate levels are also computed in the same way as for the structural responses. The output information from FPI for a given structural response includes its discrete odf values, the coefficients to represent a cumulative distribution function, sensitivity factors of the primitive variables for probabilistic structural responses.

\section{NUMERTCAL EXAMPLES AND DISCUSSIONS}

A cylindrical shell of dimensions shown in figure (3) is analyzed by IPACS. Four vertical stringers and three circumferential frames shown in figure 3(a) are used to strengthen the shell-skin structure shown in figure $3(\mathrm{~b})$. Three hundred and twelve nodes, including ninety six duplicate nodes, are used to model the structure for the finite element analysis. The graphite/epoxy composite structure is partially fixed at one end by translational and torsional springs and is free at the other end as shown in figure 4 (a) and $4(\mathrm{~b})$. The average ply thickness for the shell skin is 0.005 inches with a $[0,-45,45,90]_{s}$ composite configuration. The average ply thickness for the stringers are 0.05 inches with 10 zero degree plies.

The primitive variables identified at constituent level are: (1) 17 fiber material properties, (2) 12 matrix material properties as listed in Table 1. At the ply level, the fabrication variables are: (1) fiber volume ratio, (2) void volume ratio, (3) ply orientation and (4) ply thickness. Their statistical data are listed in Table 2. At structural level, translational and torsional spring constants for boundary rigidity are modeled as uncertain parameters. Uncertainties are also assigned to those nodes on the free edge of the vertical stringers in their out-of-plane directions. Their statistics are shown in Table 3. Three probabilistic analyses are performed: (1) buckling analysis, (2) static analysis and (3) natural frequency analysis. Ninety three uncertain primitive variables are considered including sixty six variables from stringer and skin at the constituent and ply levels, three variables for the uncertain boundary conditions and twenty four out-of-plane nodal uncertainties in the vertical 
stringers.

BUCKITNG ANALYSIS

The probabilistic critical buckling load is computed. The cumulative distribution function (cdf) of the buckling load is plotted in figure 5. The sensitivity factors of the six most important primitive variables for the critical buckling load at 0.005 cumulative probability are plotted in figure 6 . It shows that the probabilistic buckling load is most sensitive to the ply thickness, followed by fiber volume ratio, fiber modulus of the skin and stringer ply thickness, respectively. The uncertainty in the torsional springs stiffness also has some effect on the scatter of the probabilistic buckling load.

FREQUENCY ANALYSIS

Frequency analysis is also conducted. The mean value of the first natural frequency is $1.1 \mathrm{rad} / \mathrm{sec}$. The odf of this frequency is plotted in figure 7 . The sensitivity factors of primitive variables for the natural frequency at 0.005 cumulative probability is shown is figure 8. Again, it is found that skin ply thickness is the most important variable with a sensitivity factor equal to 0.88 .

\section{STATIC ANALYSIS}

Static analysis is performed using a load equal to the critical buckling load. The displacement at the free end in the longitudinal direction is analyzed. Its odf is plotted in figure 9. The sensitivity analysis shows that the fiber modulus, fiber volume ratio and ply thickness of both skin and stringer have approximately the same contribution to the scatter of the displacement. The sensitivity factors at 0.005 cumulative probability are plotted in figure 10. Also studied are the strain and stress of the node at the fixed end in the vertical stringer. The odf of the strain and its sensitivity factors are plotted in figures 11 and 12 respectively. The odf of stress and its sensitivity factors are plotted in figures 13 and 14 respectively. The sensitivity analysis again shows that the scatter of the strain and stress all are strongly dominated by the ply thickness, fiber volume ratio and fiber normal modulus of both skin and stringers. 
A methodology is developed to computationally simulate the uncertainties in the composite structural analysis. The methodology is implemented into the computer code IPACS which can efficiently and effectively simulate the uncertain structural responses. The code is capable of handling the uncertainties in the constituent, ply and laminate levels of composite structures. A large amount of useful information such as the probability distributions of desired structural responses and the sensitivity of the probabilistic structural responses to each independent primitive variable.

\section{REFERENCES}

1. R. A. Aiello, "Composite Blade STRuctural ANalyzer (COBSTRAN) User's Manual", NASA TM-101461, 1989

2. Lind, N.C., Krenk, D., and Madsen, H.O., Methods of Structural Safety, Prentice-Hall, New York, 1985

3. Wu, Y.T. "Demonstration of a New, Fast Probability Integration Method for Reliability Analysis", Advances in Aerospace Structural Analysis, O.H. Burnside and C.H. Parr, eds., ASME, New York, 1985, pp. 63-73

4. Murthy, P.L.N., Chamis, C.C., "Integrated Composite Analyzer (ICAN), Users and Programmer's Manual", NASA TP 2515, March, 1986

\section{SYMBOLS}

$\mathrm{E}_{\mathrm{f} 11}$ : fiber modulus in longitudinal direction

$\mathrm{E}_{\mathrm{f22}}$ : fiber modulus in transverse direction

$\mathrm{G}_{\mathrm{f12}}$ : in-plane fiber shear modulus

$\mathrm{G}_{\mathrm{f} 23}$ : out-of-plane fiber shear modulus

$v_{f 12}$ : in-plane fiber Poisson's ratio

$v_{f 23}$ : out-of-plane fiber Poisson's ratio

$\alpha_{f 11}$ : fiber thermal expansion coefficient in longitudinal direction

$\alpha_{f 22}$ : fiber thermal expansion coefficient in transverse direction

$\rho_{f} \quad$ : fiber mass density

$\mathrm{N}_{f} \quad$ : number of fiber per end

$d_{f} \quad$ : filament equivalent diameter 
$\mathrm{C}_{\mathrm{f}} \quad$ : fiber heat capacity

$\mathrm{K}_{\mathrm{f11}}$ : fiber heat conductivity in longitudinal direction

$\mathrm{K}_{\mathrm{f} 22}$ : fiber heat conductivity in in-plane transverse direction

$\mathrm{K}_{\mathrm{f33}}$ : fiber heat conductivity in out-of-plane transverse direction

$\mathrm{S}_{\mathrm{fT}} \quad$ : fiber tensile strength

$\mathrm{S}_{\mathrm{fc}} \quad$ : fiber compressive strength

$\mathrm{E}_{\mathrm{m}} \quad$ : matrix elastic modulus

$\mathrm{G}_{\mathrm{m}} \quad$ : matrix shear modulus

$v_{\mathrm{m}} \quad$ : matrix Poisson's ratio

$\alpha_{\mathrm{m}} \quad$ : matrix thermal expansion coefficient

$\rho_{\mathrm{m}} \quad:$ matrix mass density

$\mathrm{C}_{\mathrm{m}} \quad$ : matrix heat capacity

$\mathrm{K}_{\mathrm{m}} \quad$ : matrix heat conductivity

$\mathrm{S}_{\mathrm{mT}} \quad$ : matrix tensile strength

$\mathrm{S}_{\mathrm{mc}}$ : matrix compressive strength

$\mathrm{S}_{\mathrm{mS}}$ : matrix shear strength

$\beta_{\mathrm{m}} \quad$ : matrix moisture coefficient

$\mathrm{D}_{\mathrm{m}} \quad$ : matrix diffusivity

fvr : fiber volume ratio

vvr : void volume ratio

$\theta_{\mathrm{p}} \quad$ : ply misaligmment

$t_{\text {psk }}:$ ply thickness of skin

$t_{\text {pst }}$ : ply thickness of stringer

$\mathrm{K}_{\mathrm{cTR}}$ : translational spring constant

$\mathrm{K}_{\text {cто }}$ : torsional spring constant

$\mathrm{C}_{\mathrm{z}}$ : out-of-plane nodal uncertainties on stringers at free edges

stdv : standard deviation

$\mathrm{M}_{\mathrm{p}} \quad$ : material properties

$\mathrm{R}$ : structural response

$\mathrm{X}_{\mathrm{i}} \quad$ : independent random variable

$\epsilon \quad$ : strain

к : curvature

N : resultant in-plane force

M : resultant moment

$\mathrm{n} \quad$ : number of primitive variables 
Table 1. Uncertain Material Properties at constituent Level for both Skin and Stringers

\begin{tabular}{|c|c|c|c|c|}
\hline & unit & $\begin{array}{c}\text { Distribution } \\
\text { type }\end{array}$ & Mean & $\begin{array}{l}\text { coefficient } \\
\text { of variation }\end{array}$ \\
\hline$E_{f 11}$ & Msi & Normal & 31.0 & 0.05 \\
\hline$E_{f 22}$ & Msi & Normal & 2.0 & 0.05 \\
\hline$G_{f 12}$ & Msi & Normal & 2.0 & 0.05 \\
\hline$G_{f 23}$ & Msi & Normal & 1.0 & 0.05 \\
\hline$v_{f 12}$ & -- & Normal & 0.2 & 0.05 \\
\hline$v_{f 23}$ & -- & Normal & 0.25 & 0.05 \\
\hline$\alpha_{f 11}$ & $\operatorname{ppm} /{ }^{\circ} \mathrm{F}$ & Normal & -0.55 & 0.05 \\
\hline$\alpha_{f 22}$ & ppm $/{ }^{\circ} \frac{F}{3}$ & Normal & 5.6 & 0.05 \\
\hline$\rho_{f}$ & $\mathrm{lb} / \mathrm{in}^{3}$ & Normal & 0.063 & 0.05 \\
\hline $\mathrm{N}_{f}^{\prime}$ & -- & constant & 10,000 & 0.00 \\
\hline$d_{f}^{T}$ & in & Normal & 0.0003 & 0.05 \\
\hline$C_{f}$ & $\mathrm{BTU} / \mathrm{in} /{ }^{\circ} \mathrm{F}$ & Normal & 0.17 & 0.05 \\
\hline$K_{f 11}$ & BTU. in $/ \mathrm{hr} /$ in $^{2} /{ }^{\circ} \mathrm{F}$ & Normal & 580 & 0.05 \\
\hline$K_{f 22}$ & BTU. in $/ \mathrm{hr} /$ in $^{2} /{ }^{\circ} \mathrm{F}$ & Normal & 58 & 0.05 \\
\hline$K_{f 33}$ & $\mathrm{BTU}$. in $/ \mathrm{hr} / \mathrm{in}^{2} /{ }^{\circ} \mathrm{F}$ & Normal & 58 & 0.05 \\
\hline$S_{f T}$ & Ksi & Weibull & 400 & 0.05 \\
\hline$S_{f C}$ & Ksi & Weibull & 400 & 0.05 \\
\hline $\mathrm{E}_{\mathrm{m}}$ & Msi & Normal & 0.5 & 0.05 \\
\hline $\mathrm{G}_{\mathrm{m}}^{\mathrm{II}}$ & Msi & Normal & 0.185 & 0.05 \\
\hline$v_{\mathrm{m}}^{\prime \prime \prime}$ & -- & Normal & 0.35 & 0.05 \\
\hline$\alpha_{m}^{m}$ & ppm $/{ }^{\circ} \mathrm{F}$ & Normal & 42.8 & 0.05 \\
\hline$\rho_{\mathrm{m}}$ & lb/ in $^{3}$ & Normal & 0.0443 & 0.05 \\
\hline $\mathrm{C}_{\mathrm{m}}$ & $\mathrm{BIU} / \mathrm{in} /{ }^{\circ} \mathrm{F}$ & Normal & 0.25 & 0.05 \\
\hline $\mathrm{K}_{\mathrm{m}}^{\mathrm{III}}$ & BTU. in $/ \mathrm{hr} / \mathrm{in}^{2} /{ }^{\circ} \mathrm{F}$ & Normal & 1.25 & 0.05 \\
\hline$S_{m T}^{m}$ & Ksi & Weibull & 15 & 0.05 \\
\hline $\mathrm{S}_{\mathrm{mc}}^{\mathrm{ml}}$ & Ksi & Weibull & 35 & 0.05 \\
\hline $\mathrm{S}_{\mathrm{mS}}^{\mathrm{mC}}$ & Ksi & Weibull & 13 & 0.05 \\
\hline$\beta_{\mathrm{m}}^{\mathrm{mil}}$ & in/in/1\%moist & Normal & 0.004 & 0.05 \\
\hline $\mathrm{D}_{\mathrm{m}}$ & $\mathrm{in}^{3} / \mathrm{sec}$ & Normal & 0.002 & 0.05 \\
\hline
\end{tabular}


Table 2. Uncertain Fabrication variables at ply level

\begin{tabular}{lllll} 
& unit & $\begin{array}{c}\text { Distribution } \\
\text { type }\end{array}$ & mean & $\begin{array}{l}\text { coefficient } \\
\text { of variation }\end{array}$ \\
\hline fvr & - & Normal & 0.60 & 0.05 \\
vvr & degree & Normal & 0.02 & 0.05 \\
$\theta_{p}$ & in & Normal & 0.00 & $0.9(\mathrm{stdv})$ \\
$t_{\mathrm{psk}}$ & in & Normal & 0.005 & 0.05 \\
$t_{p s t}$ & & 0.02 & 0.05
\end{tabular}

Table 3. Uncertain Variables at the structural level

\begin{tabular}{lllll} 
& unit & $\begin{array}{c}\text { Distribution } \\
\text { type }\end{array}$ & mean & $\begin{array}{l}\text { coefficient } \\
\text { of variation }\end{array}$ \\
\hline $\mathrm{K}_{\mathrm{cTR}}$ & lb/in & Normal & $30 \mathrm{E}+06$ & 0.30 \\
$\mathrm{~K}_{\mathrm{cTO}}$ & lb-in/rad. & Normal & $12 \mathrm{E}+02$ & 0.30 \\
$\mathrm{C}_{\mathrm{z}}$ & in & Normal & 0.0 & 0.01 (stdv)
\end{tabular}



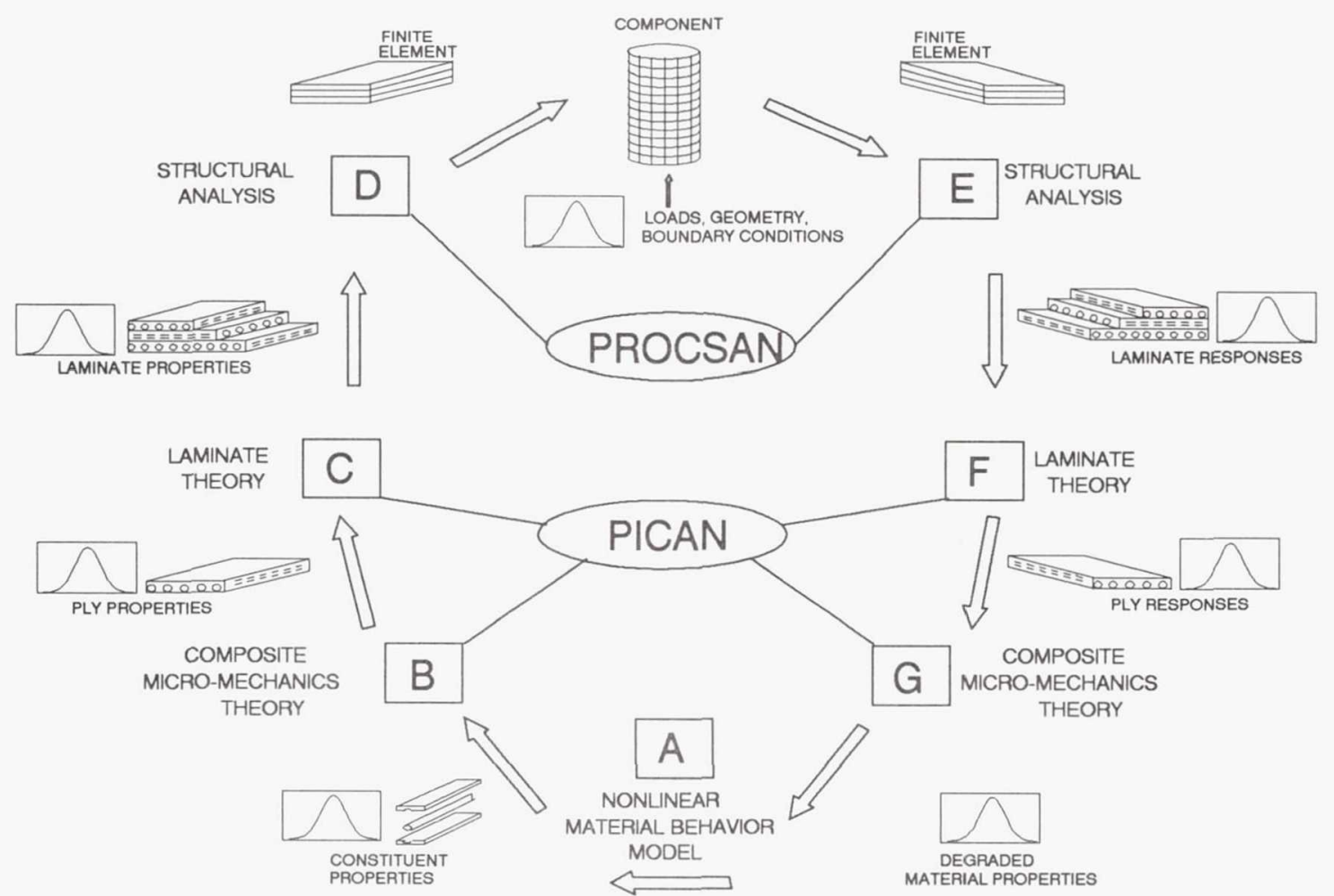

Figure 1. Concept of Probabilistic Assessment of Composite Structures

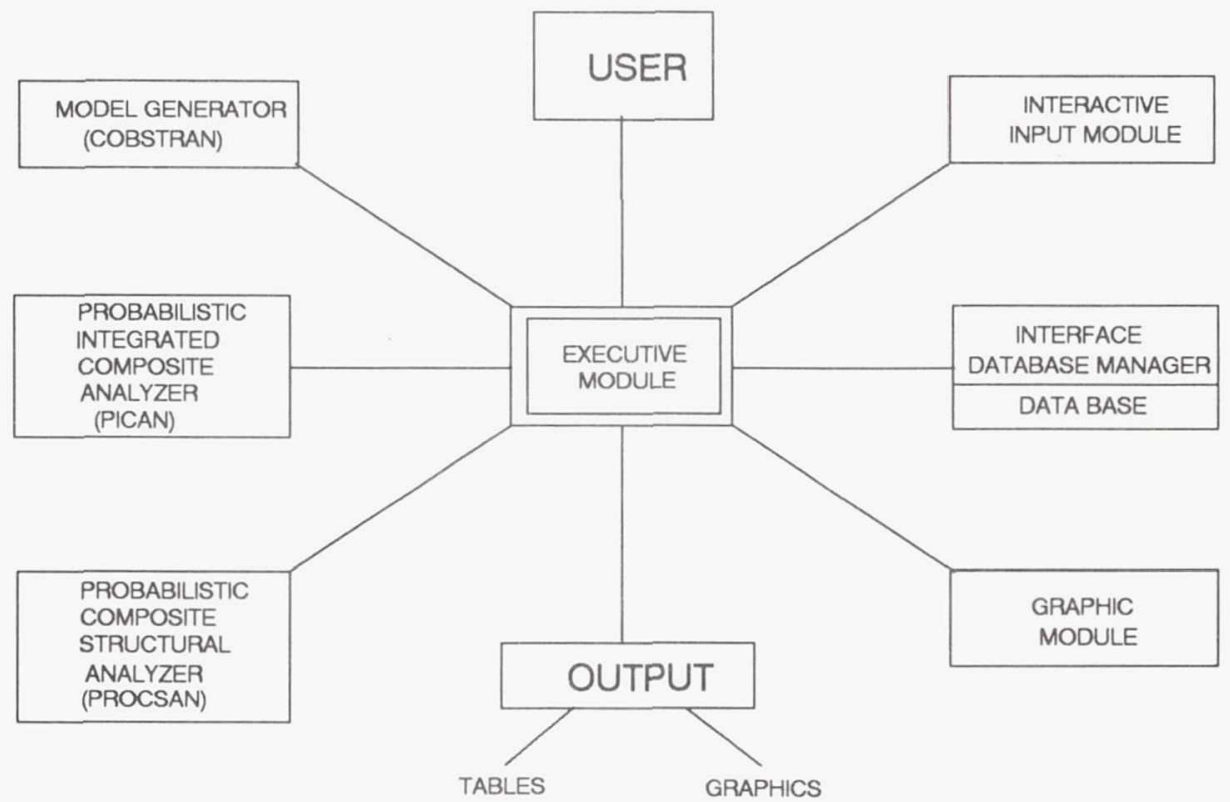

Figure 2. Architecture of IPACS Software System

(IPACS: Intergrated Probabilistic Assessment of Composite Structures) 


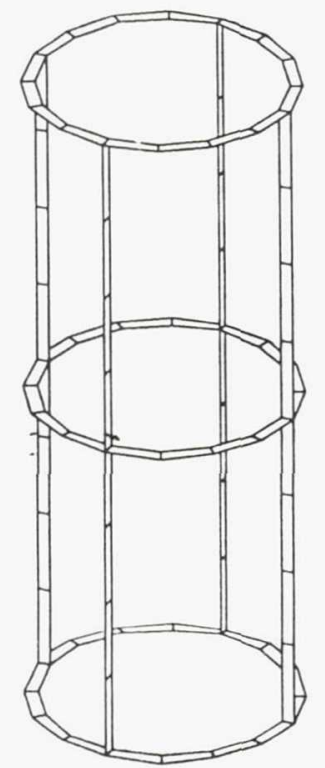

(a) frames/stringers

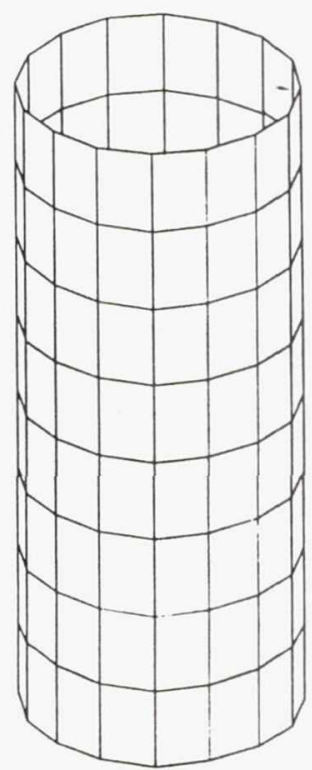

(b) skin

Figure 3. Finite Element Model of a Composite Cylindrical Shell

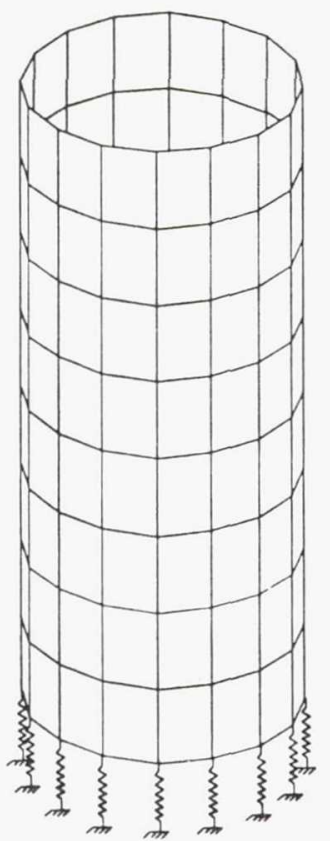

(a) translational springs

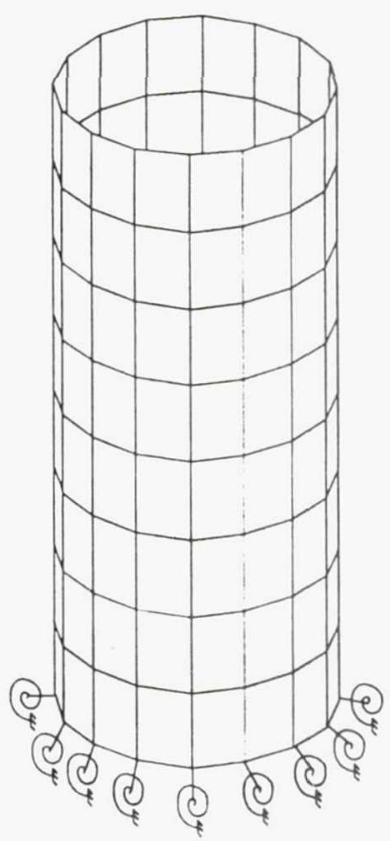

(b) torsional springs

Figure 4. Boundary Conditions of a Composite Cylindrical Shell 


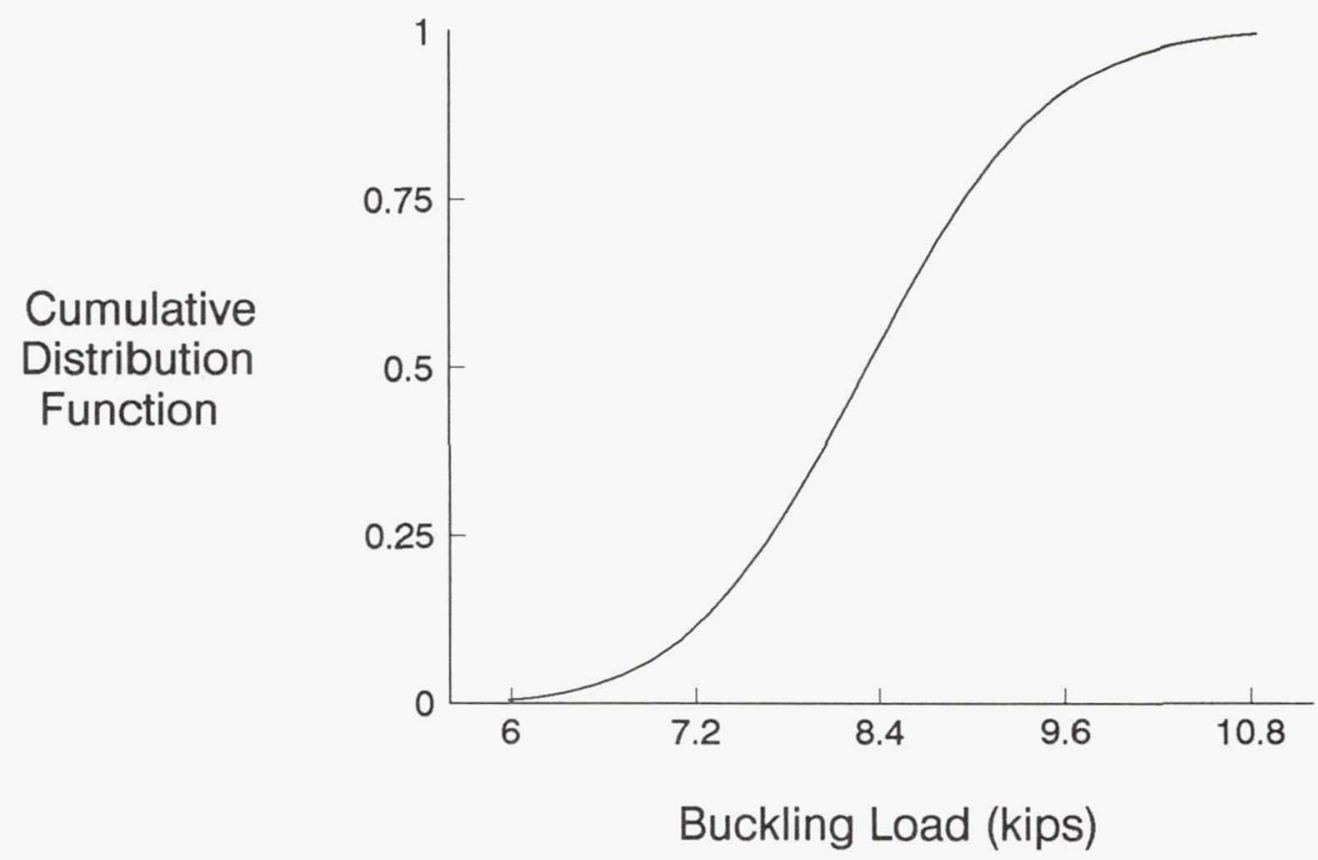

Figure 5. Cumulative Distribution function of first buckling load

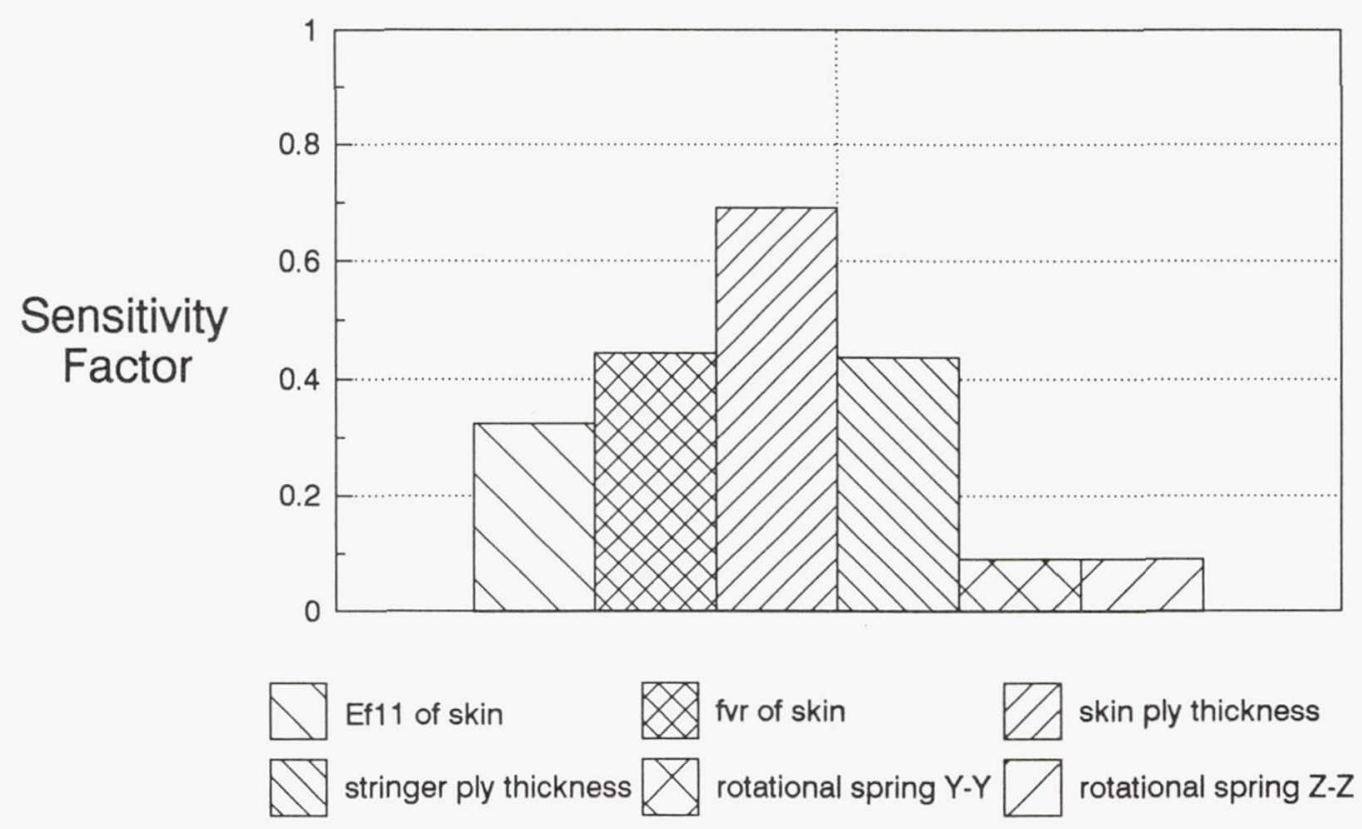

Figure 6. Sensitivity factors of six most important primitive variables for the first buckling load at probability level 0.005 


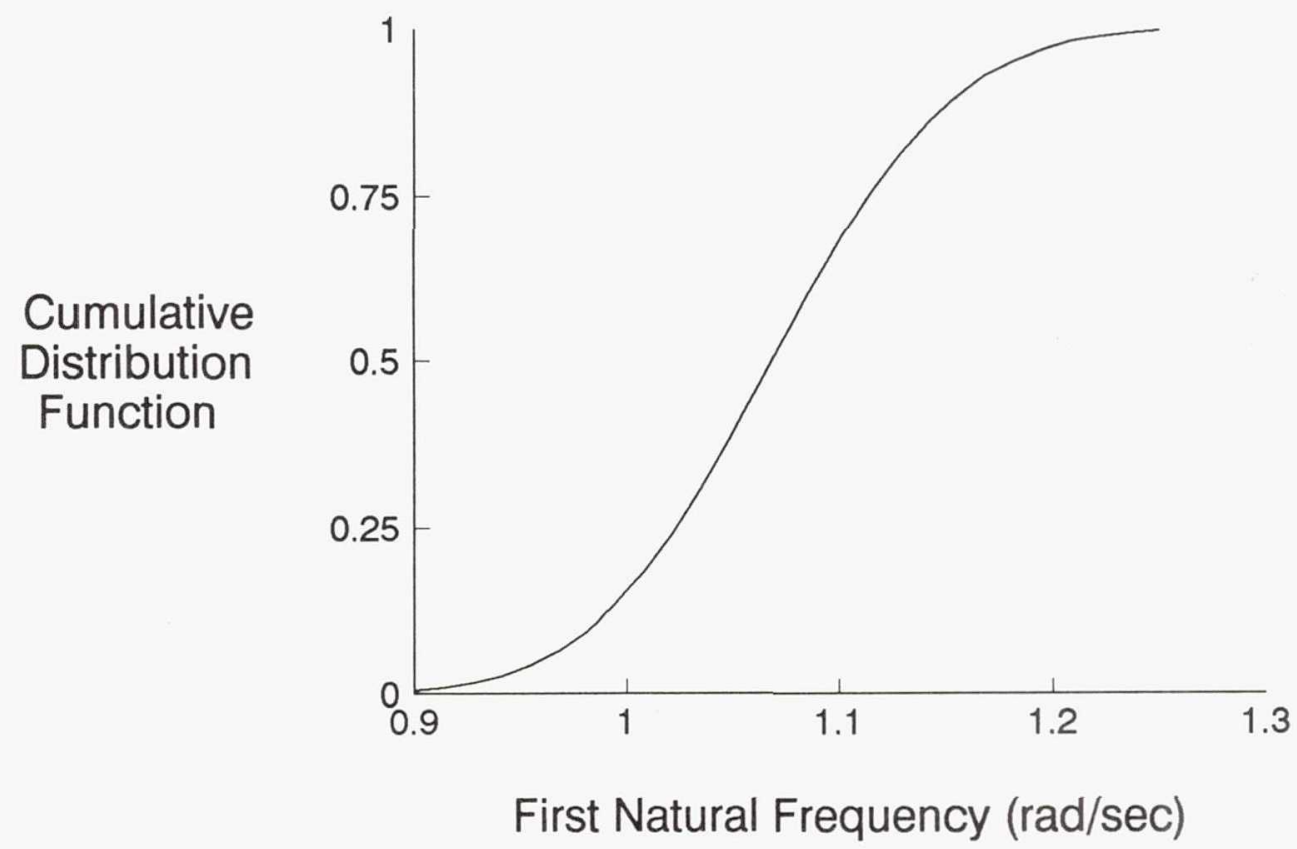

Figure 7. Cumulative Distribution function of first natural frequency

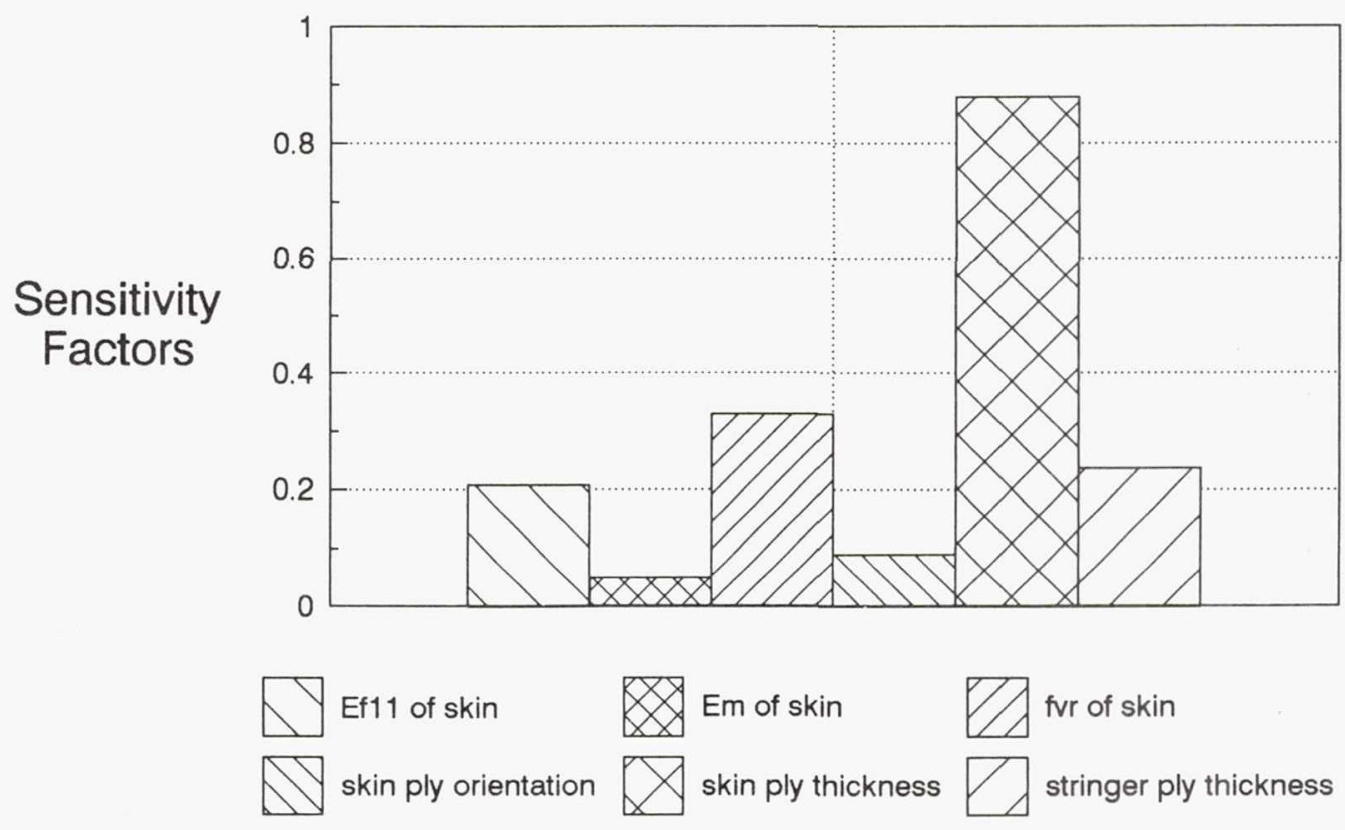

Figure 8. Sensitivity factors of six most important primitive variables for the first natural frequence at probability level 0.005 
Cumulative

Distribution

Function

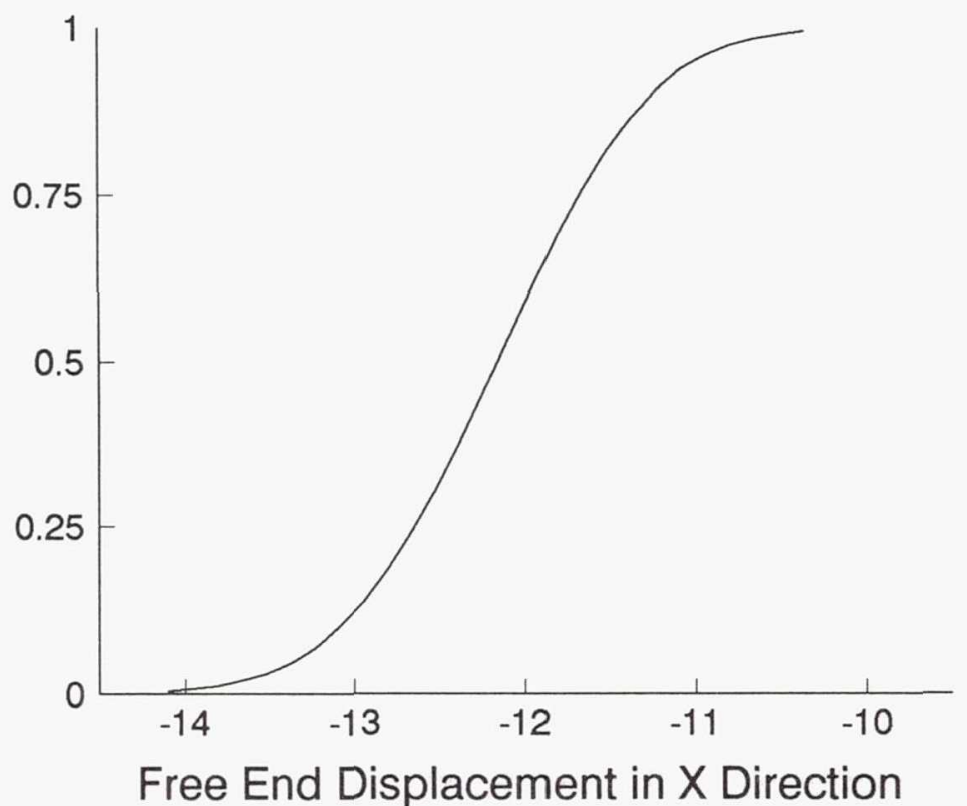

(E-03 in)

Figure 9. Cumulative Distribution function of free end displacement in $\mathrm{X}$ direction

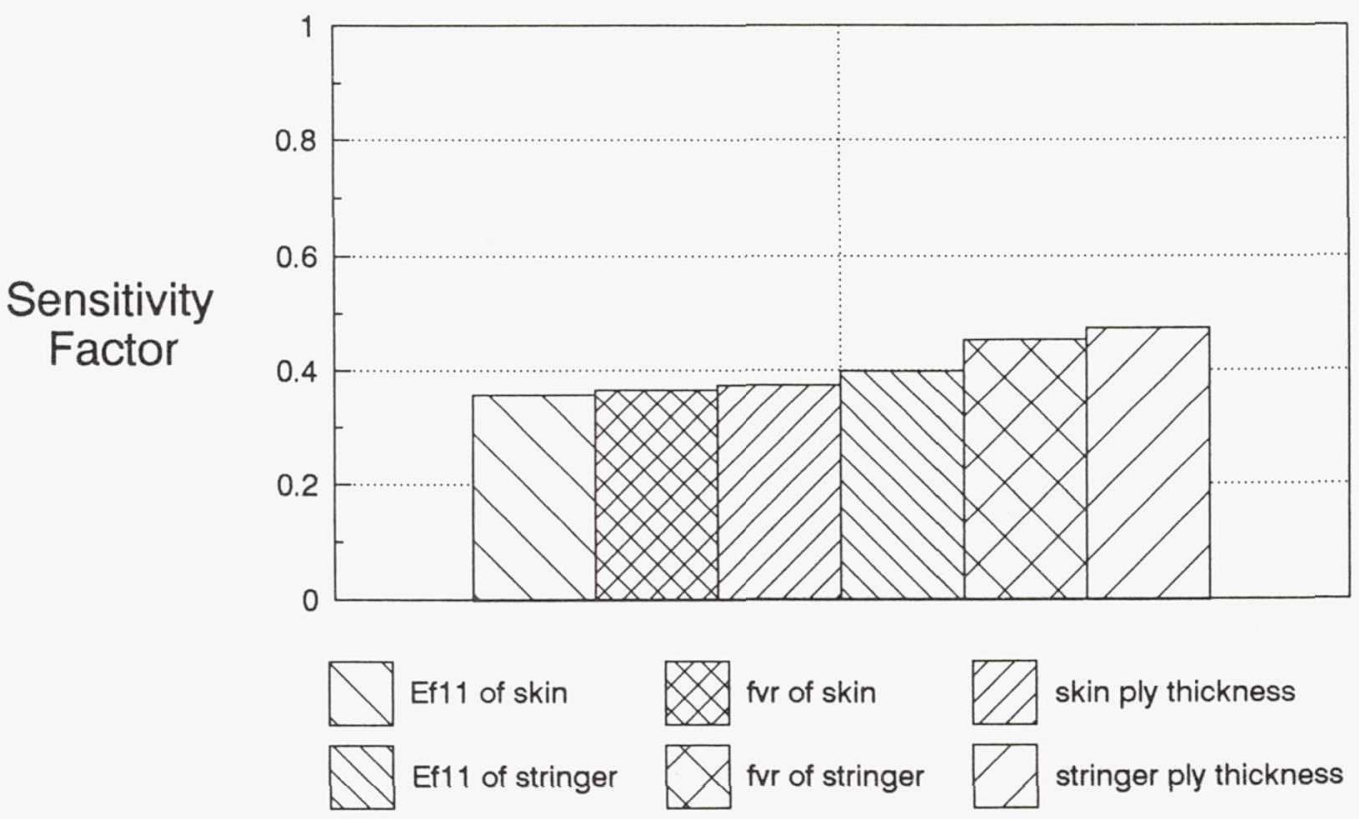

Figure 10. Sensitivity factors of six most important primitive variables for the free end displacement in $\mathrm{x}$ direction at probability level 0.005 


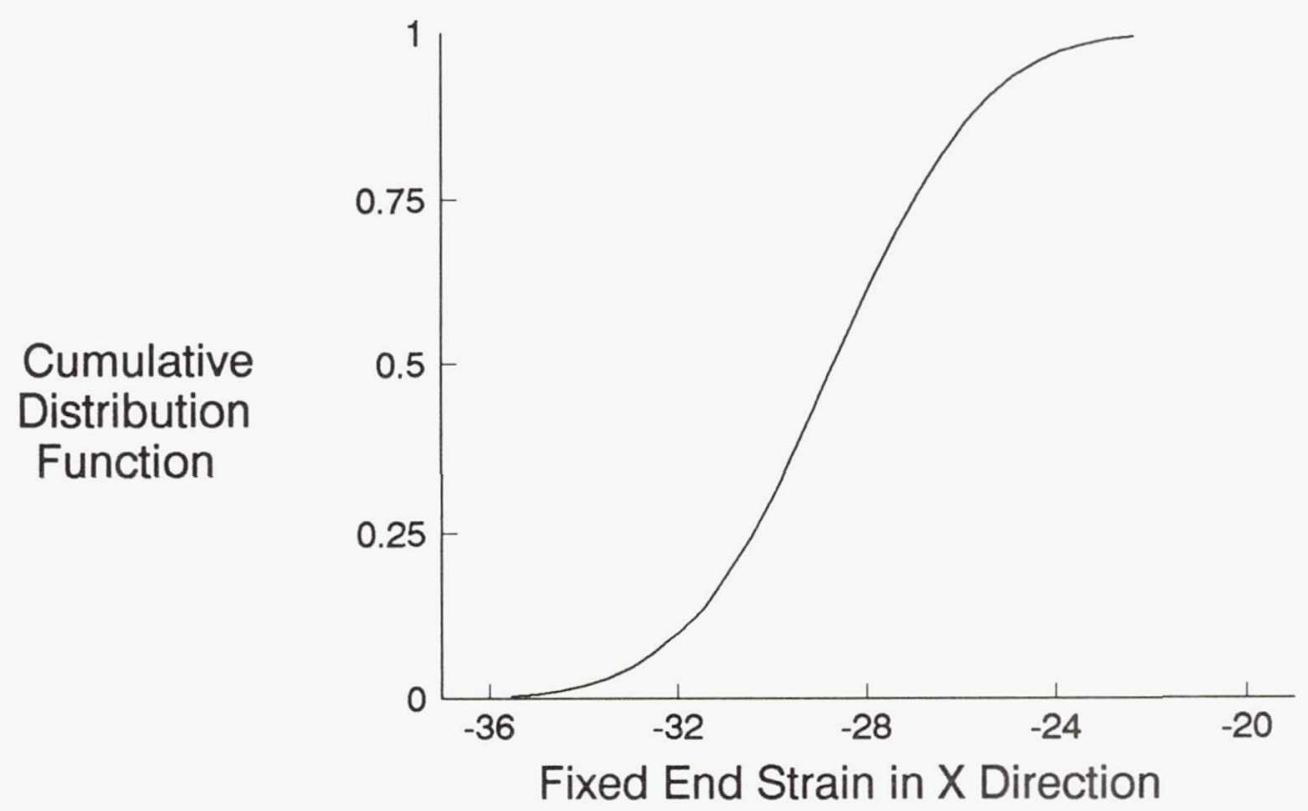

(E-06)

Figure 11. Cumulative Distribution function of fixed end strain in $\mathrm{X}$ direction

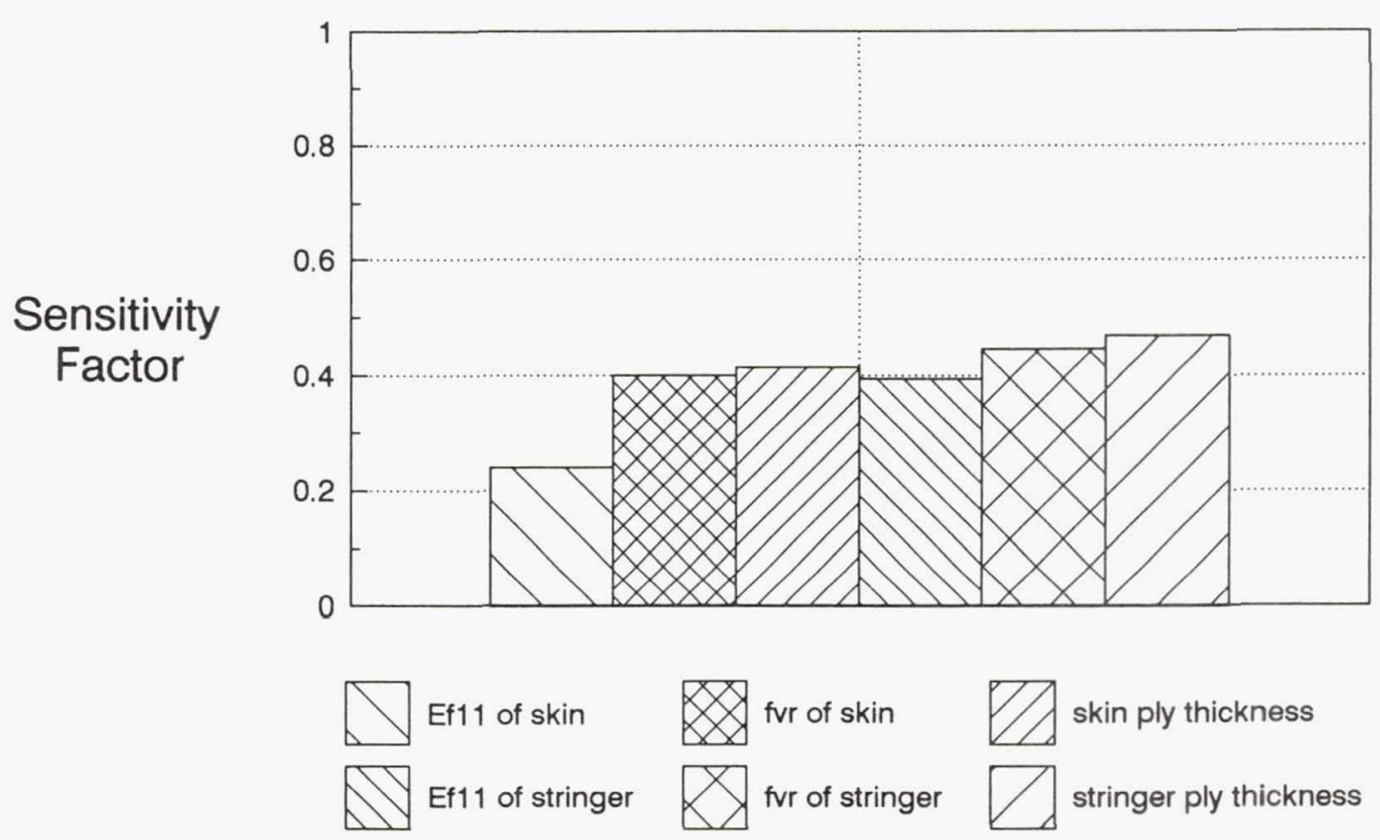

Figure 12. Sensitivity factors of six most important primitive variables for the fixed end strain in $\mathrm{x}$ direction at probability level 0.005 


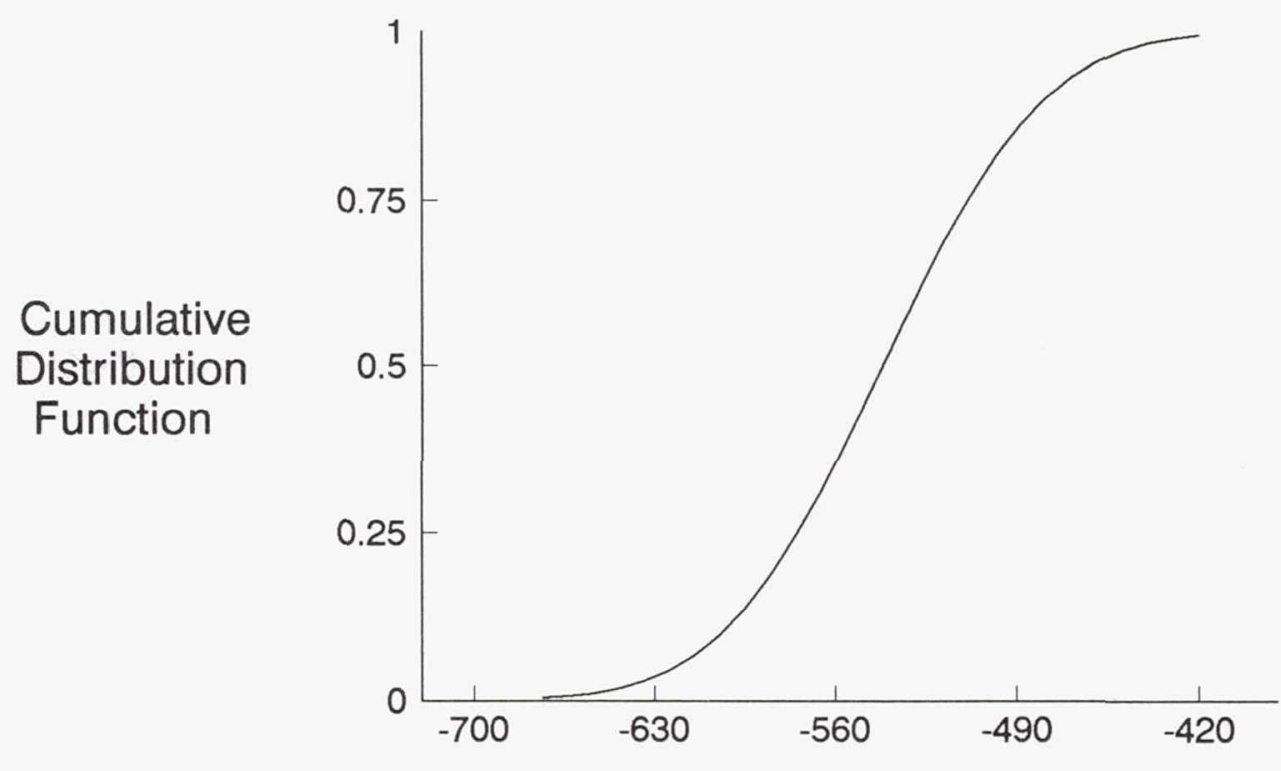

Fixed End Stress in X Direction

(psi)

Figure 13. Cumulative Distribution function of fixed end stress in $\mathrm{X}$ direction

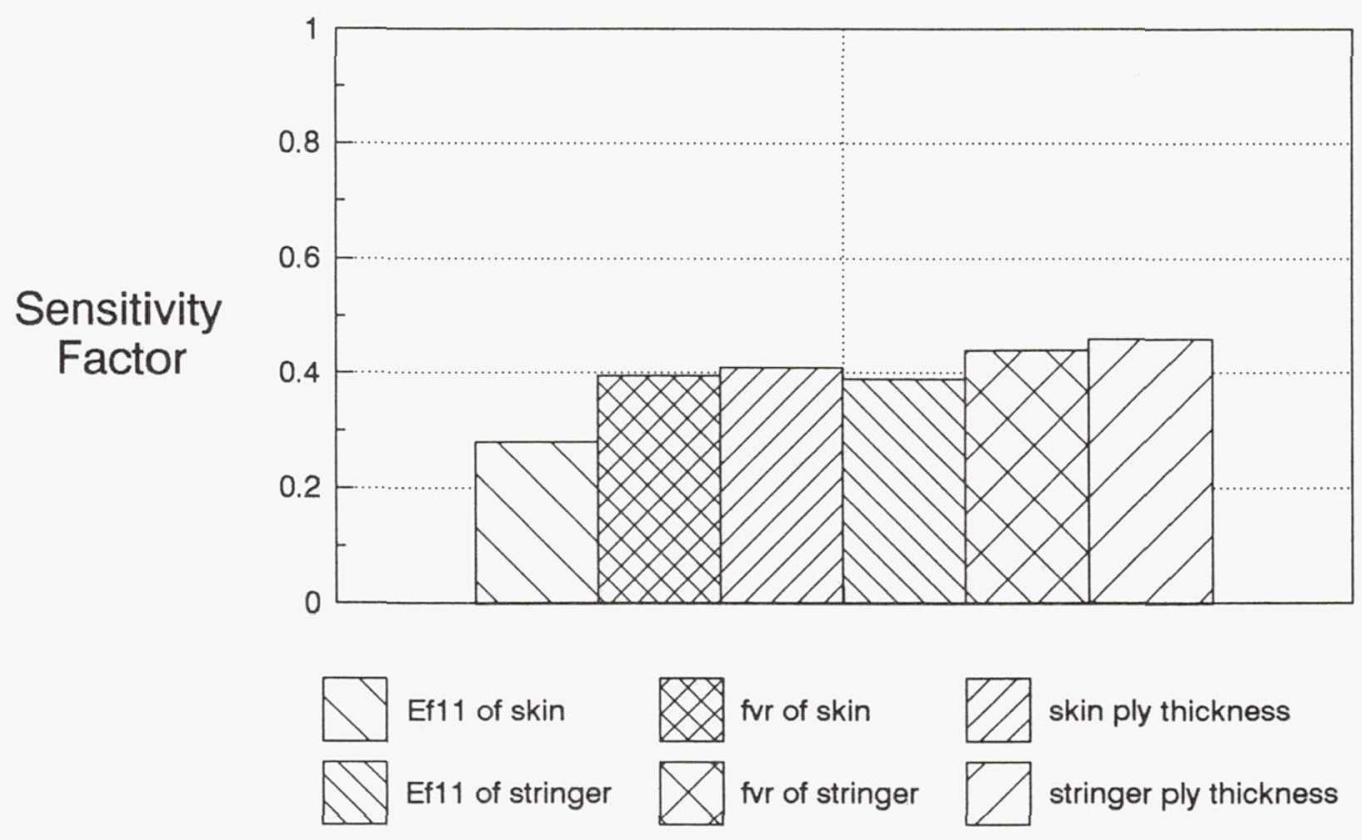

Figure 14. Sensitivity factors of six most important primitive variables for the fixed end stress in $\mathrm{x}$ direction at probability level 0.005 
Public reporting burden for this collection of information is estimated to average 1 hour per response, including the time for reviewing instructions, searching existing data sources, gathering and maintaining the data needed, and completing and reviewing the collection of information. Send comments regarding this burden estimate or any other aspect of this collection of information, including suggestions for reducing this burden, to Washington Headquarters Services, Directorate for information Operations and Reports, 1215 Jefferson Davis Highway, Suite 1204, Arlington, VA 22202-4302, and to the Office of Management and Budget, Paperwork Reduction Project (0704-0188), Washington, DC 20503.

\begin{tabular}{|l|l|l|l}
\hline 1. AGENCY USE ONLY (Leave blank) & $\begin{array}{c}\text { 2. REPORT DATE } \\
\text { November } 1991\end{array}$ & $\begin{array}{r}\text { 3. REPORT TYPE AND DATES COVERED } \\
\text { Technical Memorandum }\end{array}$ \\
\hline
\end{tabular}

\section{TITLE AND SUBTITLE}

Probabilistic Evaluation of Fuselage-Type Composite Structures

\section{AUTHOR(S)}

Michael C. Shiao and Christos C. Chamis

\section{FUNDING NUMBERS}

WU-553-13-00
7. PERFORMING ORGANIZATION NAME(S) AND ADDRESS(ES)

National Aeronautics and Space Administration

Lewis Research Center

Cleveland, Ohio 44135-3191
8. PERFORMING ORGANIZATION REPORT NUMBER

E-7348
9. SPONSORING/MONITORING AGENCY NAMES(S) AND ADDRESS(ES)

National Aeronautics and Space Administration

Washington, D.C. 20546-0001
10. SPONSORING/MONITORING AGENCY REPORT NUMBER

NASA TM-105881

11. SUPPLEMENTARY NOTES

Prepared for the Ninth DoD/NASA/FAA Conference on Fibrous Composites, Reno, Nevada, November 3-7, 1991. Michael C. Shiao, Sverdrup Technology, Inc., Lewis Research Center Group, 2001 Aerospace Parkway, Brook Park, Ohio 44142. Christos C. Chamis, Lewis Research Center, Cleveland, Ohio. Responsible person, Christos C. Chamis, (216) 433-3252.

12a. DISTRIBUTION/AVAILABILITY STATEMENT 12b. DISTRIBUTION CODE

Unclassified - Unlimited

Subject Category 39

13. ABSTRACT (Maximum 200 words)

A methodology is developed to computationally simulate the uncertain behavior of composite structures. Uncertain behavior is the consequence of the random variation (scatter) of the primitive (independent random) variables at the constituent, ply, laminate and structural levels. This methodology is implemented in the IPACS (Integrated Probabilistic Assessment of Composite Structures) computer code. A fuselage-type composite structure is analyzed to demonstrate the code's capability. The probability distribution functions of structural responses are computed. Sensitivity of a given structural response to each primitive variable is also determined from the analyses.

\section{SUBJECT TERMS}

Probability; Structure; Uncertainty; Scatter; Sensitivity; Structural; Response; Constituent; Ply; Laminate; Composite material
15. NUMBER OF PAGES 20

16. PRICE CODE $\mathrm{AO3}$

\begin{tabular}{|c|c|}
\hline $\begin{array}{c}\text { 17. SECURITY CLASSIFICATION } \\
\text { OF REPORT } \\
\text { Unclassified }\end{array}$ & $\begin{array}{c}\text { 18. SECURITY CLASSIFICATION } \\
\text { OF THIS PAGE } \\
\text { Unclassified }\end{array}$ \\
\hline
\end{tabular}

19. SECURITY CLASSIFICATION OF ABSTRACT Unclassified 
National Aeronautics and Space Administration

Lewis Research Center

Cleveland, Ohio 44135

Otficial Business

Penalty for Private Use $\mathbf{5 3 0 0}$
FOURTH CLASS MAIL

ADDRESS CORRECTION REQUESTED

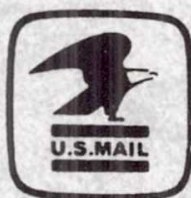

Postage and Fees Paid

National Aeronautics and

Space Administration

NASA 45 